\title{
How Open Source Has Changed the Software Industry: Perspectives from Open Source Entrepreneurs
} Juho Lindman and Risto Rajala

\author{
"In addition to the business rationale behind our" \\ decisions, there are of course the ideological reasons... \\ we wouldn't be doing this - we wouldn't have started our \\ own company - if we didn't believe in F/LOSS. \\ CEO, Tripod (a case company in this study)
}

\begin{abstract}
The emergence of F/LOSS (free/libre open source software) has triggered several changes in the software industry. F/LOSS has been cited as an archetypal form of open innovation; it consists of the convergence and collaboration of like-minded parties. An increasing number of software firms have taken upon this approach to link outsiders into their service development and product design. Also, software firms have been increasingly grounded their business models on user-centric and service-oriented operations.
\end{abstract}

This article describes a study that investigates these changes from the perspective of F/LOSS entrepreneurs. The findings are summarized into four issues that are critical in managing an F/LOSS business: i) dealing with organizational changes in the innovation process; ii) mastering user involvement; iii) successfully using resources; and iv) designing revenue models.

\section{Introduction}

The socio-technological changes pertaining to the free/libre open source software (F/LOSS) phenomenon have received increasing attention among information systems (IS) researchers. The focus of research has ranged from individual-level motivations and behavior to organizational adaptation and consequences. F/LOSS has been seen as an important driver of the information economy and an essential consideration for all software companies (Fitzgerald 2006; http://tinyurl.com7zwsn8k). In the research literature, the F/LOSS itself has been described through two distinct features. First, it is connected with licenses that provide existing and future users with the right to use, inspect, modify, and distribute modified and unmodified software to others (Von Krogh and Von Hippel, 2006; http://tinyurl.com/7747c6t). Second, it has created new communities of practice for collaborative innovation in numerous F/LOSS communities (Kogut and Metiu, 2001: http://tinyurl.com/6pexrwx; Dahlander and Magnusson, 2008: http://tinyurl.com/6w6k95q). Years of development in such communities has resulted in highquality mainstream applications.
Recent research on open innovation has emphasized the importance to understand the impact of open innovation on firms' strategies (see Harison and Koski, 2010: http://tinyurl.com/7rxbd4a; Hauge et al., 2010: http://tinyurl.com/7sdhvil). However, prior empirical studies have not paid sufficient attention to the effects of F/LOSS on the business of small and medium-sized software enterprises from the entrepreneurial viewpoint. Despite that the ideological roots of the F/LOSS phenomenon are rather well documented, the realities of the business environment deserve more attention. This study aims to fill this gap by improving the understanding of the critical issues in F/LOSS businesses and related entrepreneurial perceptions through a qualitative empirical inquiry among software entrepreneurs.

In this article, we focus on software companies that actively take part in open source software development. Bearing this in mind, we posed the following research question: What are the critical issues in managing an F/LOSS business? We addressed this question empirically through an inductive qualitative inquiry. Here, we describe narratives emerging from interviews of soft- 


\title{
Perspectives from Open Source Entrepreneurs
}

\author{
Juho Lindman and Risto Rajala
}

ware entrepreneurs and senior managers in software firms. In our analysis of these narratives, we found four categories of issues that describe the challenges rooted in the realities of managing an F/LOSS business successfully. These lessons from practitioners add an important perspective to the theoretical knowledge of the changes the F/LOSS phenomenon has brought to the software industry.

\section{Emergence of Open Innovation in Software Companies}

The benefits of open innovation are widely accepted in open source software development communities (e.g., Von Hippel and Von Krogh, 2003; http://tinyurl.com/ 7w46h24). In its broadest sense, software innovation refers to research and development (R\&D) activities that involve intellectual capital, physical products, and processes in software production (Vujovic and Ulhoi, 2008; http://tinyurl.com/83za6ut). Chesbrough (2003; http://tinyurl.com/cgu9u7w) observed that strategic innovations have typically been regarded as company's most valuable competitive assets, which also serve as barriers to entry by competitors. This kind of proprietary development and competition is characteristic of closed innovation processes, where technological progress has generally been kept secret to capture the potential for extraordinary returns (Meyer, 2003; http://tinyurl.com/ czo6ob9). Conversely, in an open environment, a company's ability to remain competitive increasingly relies on utilizing accessible resources in the continuous development of new and superior products and services. In business environments characterized by growing instability, this approach enables them to remain competitive (Vujovic and Ulhoi, 2008; http://tinyurl.com/83za6ut).

The "F/LOSS phenomenon" describes a new paradigm for the management of software-intensive innovation as well as the development and delivery of software. Using this approach, firms work with external partners and users to develop their internal innovations and obtain resources related to external innovations that complement their offerings. Currently, F/LOSS has established positions in several market segments, ranging from operating systems, middleware, and enduser products, such as media players, office suites, and games (Von Krogh and Spaeth, 2007; http://tinyurl.com/ c82ernz).

Most research on the domain has focused on successful F/LOSS projects (Radtke et al., 2009; http://tinyurl.com/ d8mezja) and open source development approaches, rather than responding to the growing interest in F/LOSS among companies (Osterlie and Jaccheri, 2007; http://tinyurl.com/7hum94f). Prior research on making commercial use of $\mathrm{F} / \mathrm{LOSS}$ has primarily focused on guidance for managers when considering whether or not to adopt F/LOSS (see Ven et al., 2008: http://tinyurl.com/6tgwkhg; Fitzgerald, 2009: http://tinyurl.com/8y3qqcs). Adoption for the wrong reasons can harm the organization; whereas not adopting F/LOSS might be a missed opportunity (Ven et al., 2008).

The emergence of F/LOSS facilitates access to resources and the use of capabilities as the source of competitive advantage among software vendors. Service-dominant logic (Vargo and Lush, 2004; http://tinyurl.com/4zt926w) describes a significant transition in business in terms of the use of resources. It considers resources in the development and delivery of offerings as operand resources (i.e., those in which an operation, or act, is performed) and operant resources (i.e., those that act on other resources). F/LOSS development depends, to a great extent, on resources that are external to a firm. The operand resources include, for example, the physical resources required to make services available to customers, while the operant resources, such as the requisite skills, knowledge, and capabilities, represent the intangible resources of the parties engaged in the collaboration. In F/LOSS businesses, resources are accessed through collaborative relationships between two or more parties, or, as suggested by Dahlander and Magnusson (2005; http://tinyurl.com/88djuec), in a company-community relationship.

There is an ongoing discussion regarding the principles that software companies should adopt when leveraging F/LOSS (Dahlander and Magnusson, 2005; http://tinyurl .com/88djuec). Ljungberg (2000; http://tinyurl.com/6ocuucm) argues that collaborative relationships include reciprocal obligations, which enact social relationships between the actors. Dahlander and Magnusson (2005) add that understanding the nature of the relationship is crucial to conducting business in a way that engages commercial and non-commercial actors.

\section{Methodology}

In this study, our goal was to elucidate the perceptions and practices of entrepreneurs that are engaged in the development of open source software. For this reason, we selected as the key informants in our study software entrepreneurs or senior managers of firms that have en- 


\title{
Perspectives from Open Source Entrepreneurs
}

\author{
Juho Lindman and Risto Rajala
}

gaged with in F/LOSS activity and are responsible for the company's strategic decisions. Arguably, they represent the most influential individuals in their firms' business model decisions although we acknowledge that the responses reflect only the "opinions of the few." However, we want to stress that CEOs and founders have a particular point of view that reflect the managerial viewpoint, which can be considered salient regarding the changes in their business.

We selected five F/LOSS companies to determine how their managers perceived and described the ongoing changes in their environment. The respondents and their firms are anonymized in this paper. The method used for data collection included semi-structured, inperson interviews and an extensive set of secondary data on the case companies. We conducted interviews with each of the respondents from the selected firms over a five-year period (2004 to 2008). To gain a rich understanding about the organizations in their contexts, we interviewed the entire staff then employed by Tripod ( 3 persons), Yoga ( 1 person), and Tulip (5 persons). For larger the companies - OurDB and Nemesis - we limited our discussions to the CEOs and CTOs.

This study uses a narrative approach to interpret the stories of F/LOSS entrepreneurs and senior managers. Ramiller and Pentland (2009; http://tinyurl.com/8xuk6x8) stated that: "A story involves actors undertaking actions intended to accomplish certain goals by certain means, within specific settings, leading to particular outcomes." In our analysis, we adopt Ramiller and Pentland's approach and structure our findings by focusing on the actions, goals, means, and outcomes (pertaining to F/LOSS activities) emerging from the narratives of our interview subjects. There is an assumption that, by analyzing how stories are told and what their tellers say and do not say, we can discover the hidden meaning behind the world they describe (Burr, 1995; http://tinyurl.com/6pbzvdw).

\section{Findings: Critical Issues in Managing F/LOSS Businesses}

Interviews with the F/LOSS entrepreneurs provided a view of the realities of managing F/LOSS businesses. The narratives gathered from these interviews included a mixture of the entrepreneurs' personal experiences and their tried-and-true organization-level business practices. Moreover, they illustrate how the respondents view their business environment and the factors upon which they base their decision-making.
F/LOSS induces user involvement in software development Integrating user feedback and requirements to the software was seen as one of the main opportunities and challenges with F/LOSS activity. The entrepreneur who founded Yoga underscored that "the main idea of F/LOSS is working together to create tools everyone wants to use individually." The interviewees emphasized that F/LOSS development was organized differently from proprietary development and thus is able to respond more promptly to customer needs.

"We would never have gained 5 million users to our database product without acting according to the principles of the open source software community. Since we first released our software under an open license, we have gathered feedback - development ideas, problem descriptions and solutions - and responded to all possible initiatives from the user community to develop the product with the skillful individuals using the product." (CEO, OurDB)

F/LOSS enables and invites user participation in software development. The narratives reveal differences in the numbers of possible contributions among the different software product categories, but are harmonious in their descriptions of the clear role users play as contributors to the software project, product, and service. In addition, the narrative of Yoga's manager shows an example of a "classic open source development". He described that his own contributions to several F/LOSS projects have been guided by his own personal needs and preferences. His contributions were motivated by the reason that the available software did not meet his personal needs. Moreover, the CEO of Nemesis narrated that:

"Our solutions are made for the customers, not for ourselves. We want to build a working solution, but we want the customers to sit down with us, so we can do it on the users' terms. We believe that it is not enough for us to provide open source software. In our opinion, customers should also have open access to the actual work process - not only through external communication, but also in internal collaboration. We want to get the customers' messages heard."

Our respondents assumed that customers had the necessary capability and willingness for the elicitation of their requirements and that this information should guide the development of software products. In this vein, customer expectations determined which solutions would become commercially viable. The signific- 


\title{
Perspectives from Open Source Entrepreneurs
}

\author{
Juho Lindman and Risto Rajala
}

ant role played by such expectations was taken for granted; the respondents assured us that customer expectations drive actual customer behavior and their identification is thus salient to software vendors.

\section{Open source development relies on external resources} One of the advantages of F/LOSS is tapping into external contribution in the innovation activity. That is, F/LOSS activity emphasizes access to external capabilities rather than internal resource ownership. Harnessing this innovation potential would allow the production of software and services that would be more tailored to users' needs. The extant research shows that, due to the search and use of external resources and capabilities, the borders between networked companies and their environments are becoming blurred (Von Hippel and Von Krogh, 2003: http://tinyurl.com/7w46h24; Vujovic and Ulhøi, 2008: http://tinyurl.com/83za6ut; Elpern, 2009; http://tinyurl.com/76hj35f).

The CEO of OurDB clarifies that external resources are of key importance to the company's success:

"The vast community of [our OurDB product] users and developers is what drives our business - we have five million server installations in use worldwide. Around them there are small "software ecosystems." There are books and articles written, lectures held, courses taught, and applications developed around our products. This community of volunteers is our most important asset. Yet, it is difficult to define."

Moreover, a respondent from Tripod described the context in which resources are publicly available, but then stated that the capability to make use of these resources to capture value potential is essential:

"With a large user group, you can attain a higher product quality, as a larger number of people use the software in different situations and provide feedback. It also limits your development costs, as you will receive some of the software from others. Sometimes, the greatest ideas come from outside - ideas that you never had thought of. Users often widen our view." (Project manager, Tulip)

In a related exchange, the original developers share the code in the F/LOSS community, and the clients gladly rely on the developers' knowledge in applying the code in the development of applications, consultancy, training, and maintenance of the software.
According to our narratives, the ability to utilize external resources and capabilities is recognized as one of the key factors in remaining competitive in the software industry. As public goods, F/LOSS-based platforms, components, and applications shift the focus from the development of proprietary innovations to the use of the goods and knowledge that are publicly available.

Open source development encourages open innovation The openness of innovation activity is a key theme in commercial F/LOSS development (Chesbrough, 2003: http://tinyurl.com/cgu9u7w; Watson et al., 2008: http://tinyurl.com/coemo53). The manager of Tripod argues that this kind of a joint project will succeed "only if you let people see that their response has some effect on the software." The responses depict a fundamental difference between open and closed innovation paradigms. "There was a lot to do with our software before it was ready, but we opened in a very early stage. We were able to give plausible promise and thus received a lot of valuable feedback. This resulted in a quite different end product." (Manager, Tripod)

Hence, the quality of innovation outputs is an essential reason to engage in open innovation. The open innovation approach embodies working together with numerous partners and various members of the F/LOSS community. In such an innovation model, the feedback loops are short and the software benefits from continuous improvement.

Our narratives underscore that, through F/LOSS activity, firms open their innovation processes to benefit from the knowledge and the innovation capacity of diverse open source communities. In this way, firms aim to benefit from the innovation capacity of both developers and users, resulting in shorter lead-times, shorter times to market, and ultimately, better product quality.

F/LOSS-based public goods change the revenue models The CEO of OurDB claims that the entire business "will face a fierce price war, where profits disappear". A vital consideration in F/LOSS activity is how it changes the means of value capture in software businesses. During the interviews, our respondents tended to discuss services, rather than products. The respondents agree that proprietary software cannot compete successfully for long in the same market as a complementary F/LOSS product. 


\title{
Perspectives from Open Source Entrepreneurs
}

\author{
Juho Lindman and Risto Rajala
}

"Basically, our revenue streams are very broad and farfetched. So, any reduction of problems in our service reduces cost and is actually an increase in our profit" (Project manager, Tulip). Our narrators discussed their revenue strategies at length, including the following statement from the CEO of OurDB: "Enterprise software buyers are tired of complex pricing models (per core, per $C P U$, per power unit, per user, per whatever the vendor feels like that day) - models that are still in use by the incumbents. [With OurDb], you pay by service level and the number of servers. No nonsense, no special math."

The case firms in this study have experimented both with revenue models that are directly product or service-related and those that indirectly benefit from the large user base:

"In the beginning we did not focus on profits at all. Instead, we focused on boosting the use of the software. The vast community of users and developers is what drives our business. Then we sell our offerings to firms - those who need to scale and cannot afford to fail. The enterprise offering consists of certified binaries, updates and upgrades, automated DBA services, $7 \times 24$ error resolution, etc." (CEO, OurDB)

The narratives underscore that the software delivery price as such is not a key purchasing criteria, but the total cost of ownership, including all transaction costs and lock-in costs, is of greater concern. The manager of Yoga claims that the strength of F/LOSS is that, in many cases, it is the most cost-efficient solution:

"Some proprietary software companies communicate - and in some cases quite correctly - that the total cost of ownership of their products is lower the total cost incurred from an open source software installation. In some cases it may be true, but in others, the cost comparison clearly favors the open source software."

However, our interviewees share the view that, when software is distributed freely, traditional revenue sources wane and firms are compelled to develop novel revenue models that may be based on services and may be only indirectly bound to the distribution of software licenses.

\section{Conclusion}

The lessons learned from the experiences of the entrepreneurs in this study indicate that F/LOSS-based soft- ware development urges software innovators to open up their innovation processes in a way that calls increasing attention to user involvement throughout the software development and delivery processes. That is, the F/LOSS activity emphasizes a need to maintain access to external capabilities, rather than leaning on internal resource ownership. In addition, entrepreneurs and managers should consider the objectives of the open innovation activity, because F/LOSS-based public goods change the focus of competition in the software business from product-centric to service-centric operations. These findings are summarized in Table 1 and are described in greater detail below.

The amount and nature of user involvement in software development and delivery, which is characteristic in the F/LOSS activity, would take many long-haul software entrepreneurs by surprise. In fact, our narratives indicate that rich social interactions with users may bring challenges even for experienced F/LOSS entrepreneurs. However, our informants are harmonious in describing the benefits of rich user interactions for gaining user insight and increased understanding of users' needs and wants, and they agree that these benefits clearly exceed the burden of managing extensive user interactions. These findings are in accordance with the arguments presented by Fitzgerald (2006; http://tinyurl.com/7zwsn8k). Moreover, user involvement may foster user commitment to the company's offerings.

In line with the finding of Vujovic and Ulhøi (2008; http://tinyurl.com/83za6ut), we found that the F/LOSS activity emphasizes access to external capabilities, rather than internal resource ownership. The key resources include developer capabilities and skills as well as readily available F/LOSS components. On the whole, maintaining access to relevant capabilities seems to be far more rewarding than efforts to assimilate new resources. This was grounded mainly on the reasoning that, if some companies provide their software as "public goods", the managers of all firms providing competing offerings must rethink the rational for maintaining in-house resources. The narratives express that increased utilization of external resources has long-term effects on the whole software industry. That is, companies that do not endorse F/LOSS will also face changes in regard to resource availability and costs.

Our informants described significant productivity enhancements related to collaborative innovation pro- 


\section{Perspectives from Open Source Entrepreneurs}

\section{Juho Lindman and Risto Rajala}

Table 1. Summary of findings including implications for managers of firms engaged in F/LOSS development

\begin{tabular}{lll}
\hline Essential themes & Key considerations & Managerial actions \\
\hline $\begin{array}{l}\text { Actions: User } \\
\text { involvement }\end{array}$ & $\begin{array}{l}\text { F/LOSS activity emphasizes user } \\
\text { involvement in software development } \\
\text { and delivery. }\end{array}$ & $\begin{array}{l}\text { Orient the firm toward richer } \\
\text { social interactions with the } \\
\text { users. }\end{array}$ \\
\hline $\begin{array}{l}\text { Means: Utilizing } \\
\text { external resources }\end{array}$ & $\begin{array}{l}\text { F/LOSS activity emphasizes access } \\
\text { to external capabilities, rather than } \\
\text { internal resource ownership. }\end{array}$ & $\begin{array}{l}\text { Maintain access to relevant } \\
\text { capabilities rather than } \\
\text { assimilate new resources. }\end{array}$ \\
$\begin{array}{lll}\text { Goals: Managing } \\
\text { the open innovation } \\
\text { processes }\end{array}$ & $\begin{array}{l}\text { F/LOSS-based software development } \\
\text { urges software innovators to open up } \\
\text { their innovation processes. }\end{array}$ & $\begin{array}{l}\text { Consider the purpose of } \\
\text { external contribution in the } \\
\text { innovation process. }\end{array}$ \\
\hline $\begin{array}{l}\text { Outcomes: } \\
\text { Revenue models }\end{array}$ & $\begin{array}{l}\text { F/LOSS-based public goods change } \\
\text { the revenue models of firms taking } \\
\text { part in open source development. }\end{array}$ & $\begin{array}{l}\text { Grasp the logic of generating } \\
\text { revenues from increasingly } \\
\text { service-oriented offerings. }\end{array}$ \\
\hline
\end{tabular}

*Fitzgerald, 2006: http://tinyurl.com/7zwsn8k

†Vujovic and Ulhøi, 2008: http://tinyurl.com/83za6ut; Rajala, 2009: http://tinyurl.com/d6bkev9

$\ddagger$ Watson et al., 2008: http://tinyurl.com/coemo53

cesses. Our findings highlight that in order to capture the full potential from external contribution in open innovation, managers should try to engage the users or other external contributors already at the early phases of their innovation processes. However, the interviewees emphasized the importance of understanding the purpose such openness and to consider the aims for external contribution in the innovation process. If the goal for collaboration is clear, it would be easier to reveal even the once confidential information, as the innovators are surged forward with enthusiasm, bearing barely in mind that what parts of the innovation should be kept secret to ensure the future presence in the business. These findings are congruent with the views of Watson et al. (2008; http://tinyurl.com/coemo53).
F/LOSS-based public goods change the revenue models of firms taking part in open source development. In our data, it is evident that F/LOSS has an impact on the software industry as a whole, as it degrades traditional sources of revenue and compels firms to develop new revenue models primarily based on services. The interviewed executives recounted the need to grasp the logic of generating revenues from increasingly service-oriented offerings. This is congruent with prior studies on open source software business. Our findings are also consistent with existing studies on F/LOSS business models, and underscore that new revenue models are increasingly grounded on services. These F/LOSS-induced changes can affect all firms in the software industry and are not limited to companies engaged in F/LOSS activity. 


\title{
Perspectives from Open Source Entrepreneurs
}

\section{Juho Lindman and Risto Rajala}

\begin{abstract}
About the Authors
Juho Lindman is an Assistant Professor in the Hanken School of Economics in Helsinki, Finland. Juho defended his doctoral dissertation focusing on open source software development organization in the Aalto University School of Economics in Helsinki. In the field of information systems science, his current research is focused in the areas of open source software development, open innovation, open data and organizational change.

Risto Rajala is Director of Research in a multischool collaboration platform in service research and education at Aalto University in Helsinki, Finland. His recent research has been centered on usercentric and open forms of managing software-intensive innovations, the transformation of software vendors' business models, IT services and the sociotechnical aspects of service systems. Risto holds a $\mathrm{PhD}$ in Information Systems Science from the Aalto University, School of Economics. His work has been published widely in refereed scientific journals, international conference proceedings, academic books, and other scientific volumes. He is also a member of the Review Board of the Technology Innovation Management Review.
\end{abstract}

